\title{
ROTATION PERFORMANCE OF COLD-FORMED STEEL PORTAL FRAMES
}

\author{
M. Dundu \\ University of Johannesburg, Department of Civil Engineering Science, \\ P O Box 524, Auckland Park 2006, South Africa \\ *(Corresponding author: E-mail: mdundu@uj.ac.za)
}

Received: 4 January 2012; Revised: 23 April 2012; Accepted: 11 May 2012

\begin{abstract}
Design based on linear-elastic analysis has been found not to provide an accurate representation of the behaviour of steel structures. The introduction of limit state design created the expectation that ultimate limit state would be based on inelastic behaviour. Opportunities for ultimate resistances to be calculated using plastic stress blocks is available in design codes, however designers still assess ultimate load and action effects using elastic analysis. An experimental and theoretical investigation of a cold-formed steel portal frame is done to try and address this problem. The rafter and column members are formed from single cold-formed channel sections, which are bolted, back-to-back at the eaves and apex joints, and connected to the foundation through angle irons. The design of the frame members follows the traditional approach of applying the effective width method to control local buckling, followed by an assessment of cross-sectional and buckling requirements. However, the yield and overall buckling requirements are modified by a factor of 0.8 to account for stress concentrations, shear lag and bearing deformations in the connections. The non-linear moment-rotation response exhibited late in the loading sequence of structures 1,3 and 4 is attributed, primarily, to bolt-bearing deformation and local yielding of the flange below the inside bolt. It is demonstrated both experimental and conveniently using the mixed flexibility approach that such frames can achieve the required rotation capacity needed for inelastic analysis.
\end{abstract}

Keywords: Frame, Single cold-formed channels, Eaves and apex joints, Points of contraflexure, Mixed flexibility approach, Rotation capacity, Plastic analysis.

\section{INTRODUCTION}

In plastic design of hot-rolled portal frames, various regions in the structure are required to form plastic hinges. Plastic hinges progressively form at points of maximum moment until a mechanism is formed. The hinges must be capable of reaching the plastic moment $\left(\mathrm{M}_{\mathrm{p}}\right)$ and maintaining the plastic moment for a suitable amount of plastic hinge rotation, to allow for redistribution of bending moments in a frame. For this to happen, the points where the hinge is formed must have sufficient ductility to allow adequate rotation before the frame collapses. To provide adequate hinge rotation, the plastic deformation may occur within the connection or in the adjacent member. Since the connections under consideration are not stiffened as in hot-rolled portal frames the required hinge rotation must be provided by the connection. Ductility of the connection is therefore an important aspect of this investigation, as the frames are made of cold-formed channels and cold-formed channels are known to possess limited rotation capacity. The purpose of this investigation is to assess rotation performance of the connections and their ability to form plastic hinges, and thus allow for the redistribution of moments.

Several benefits can be realised if the ductility of a structure can be incorporated into design. Such benefits include:

- Greater structural efficiency in terms of both flexural strength and stiffness through continuity of members,

- Provision of alternative load paths when the actual behaviour does not accord with the design assumptions, or these assumptions are in error, and

- Improved safety when loads of an unexpected or rare nature occur, such as explosions or earthquakes. 
In a typical portal frame under vertical loading a plastic hinge is expected to form at the eaves first, since this is the point of maximum moment. Vertical downward loading caused by permanent and imposed load is frequently the critical load case for low-rise structures in South Africa and the rest of the Southern African region. Assuming pinned base conditions, the bending moment diagram, shown in Figure 1, is the normal mode of failure for this region unless the frame is very tall or there is an exceptionally high wind pressure.

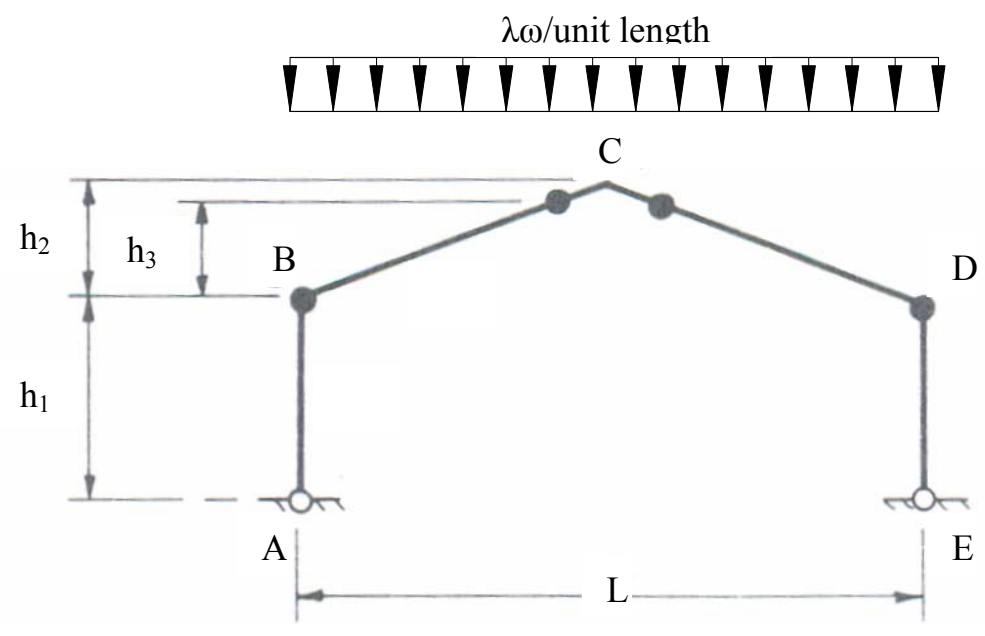

(a) Pinned Base Portal Frame with Hinges

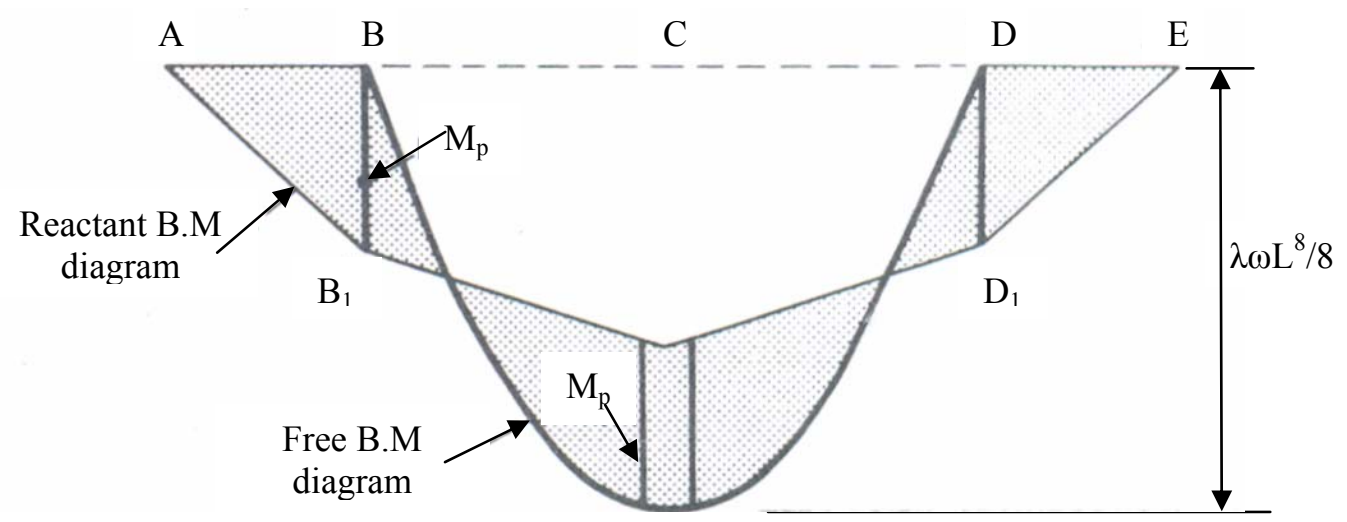

(b) Bending Moment Diagram

Figure 1. Portal Frame Subjected to Downward Loading

\section{EXPERIMENTAL MODEL}

The spans of the frames investigated ranged from $10 \mathrm{~m}-14 \mathrm{~m}$, with a constant eaves height of $3 \mathrm{~m}$ and a pitch of $10^{\circ}$. Preliminary calculations, based on SANS 10162-2-2005 [1], showed that $300 \times 50 \times 20 \times 3,300 \times 65 \times 20 \times 3$ and $300 \times 75 \times 20 \times 3$ cold-formed channel sections would be suitable for $10 \mathrm{~m}, 11$, and $12 \mathrm{~m}$ spans, respectively. This code is based on the Canadian Code, CAN/CSA-S16.01 [2]. Full-scale testing of the portal frames was avoided so that the structure could be accommodated in the laboratory and to reduce the cost. The model of the two frames was extracted from the eaves joint to the points of contraflexure in the rafter and column respectively. This represents the portion on the bending moment diagram in a typical full portal frame from the eaves joint to the point of zero moment on either side of the joint. The eaves' joint is the most highly stressed portion of the 
portal frame under vertical loading, and vertical loading is the most critical load condition in South Africa and the region.

A typical schematic diagram of the general layout of the test set-ups and degrees of freedom at the supports of structures are shown in Figure 2. The diagram was laid on the laboratory to simplify the testing procedure. The photograph in Figure 3 show the actual test arrangement, viewed from the other side. In this figure, the column and rafter sections (both of cold-formed channels) are joined together, back-to-back, by a system of bolts to generate increased strength in the connection due to counterbalancing moments and forces. One of the fundamental decisions taken at the planning stage was that the tests should simulate, as realistically as possible, the actual conditions to which a portal frame structure could be subjected under vertical loading. In a typical portal frame building, internal frames are subjected to similar loading and it is also logical to assume that when the frames are acted upon by the load they deflect downwards by the same amount. For this reason two portal frames were used in the experimental model, and subjected to equal loading. In addition these two frames would allow for interaction to occur between themselves, while at the same time avoiding structural complications and higher costs that are expected as a result of testing more frames. K-bracings (size $50 \times 50 \times 2 \mathrm{~mm}$ ) and $100 \times 50 \times 20 \times 2 \mathrm{~mm}$ cold-formed channel purlins are used to stabilise the frames.

To allow for horizontal movements to occur, $3 \mathrm{~mm}$ roller bearings were introduced into the model. A $30 \mathrm{~mm}$ diameter steel ball was introduced to allow all supports the freedom to rotate in any direction. The balls were positioned at the shear centre of the frames in order to reduce eccentricity in the set-up. The two portal frame joints were subjected to equal loads applied through pins at the points of contraflexure using two 16-tonne, hand-operated jacks. To simulate the condition of the eaves joint in Figure 1, the frames in Figure 3 were jacked inwards to create an external moment at the joint.

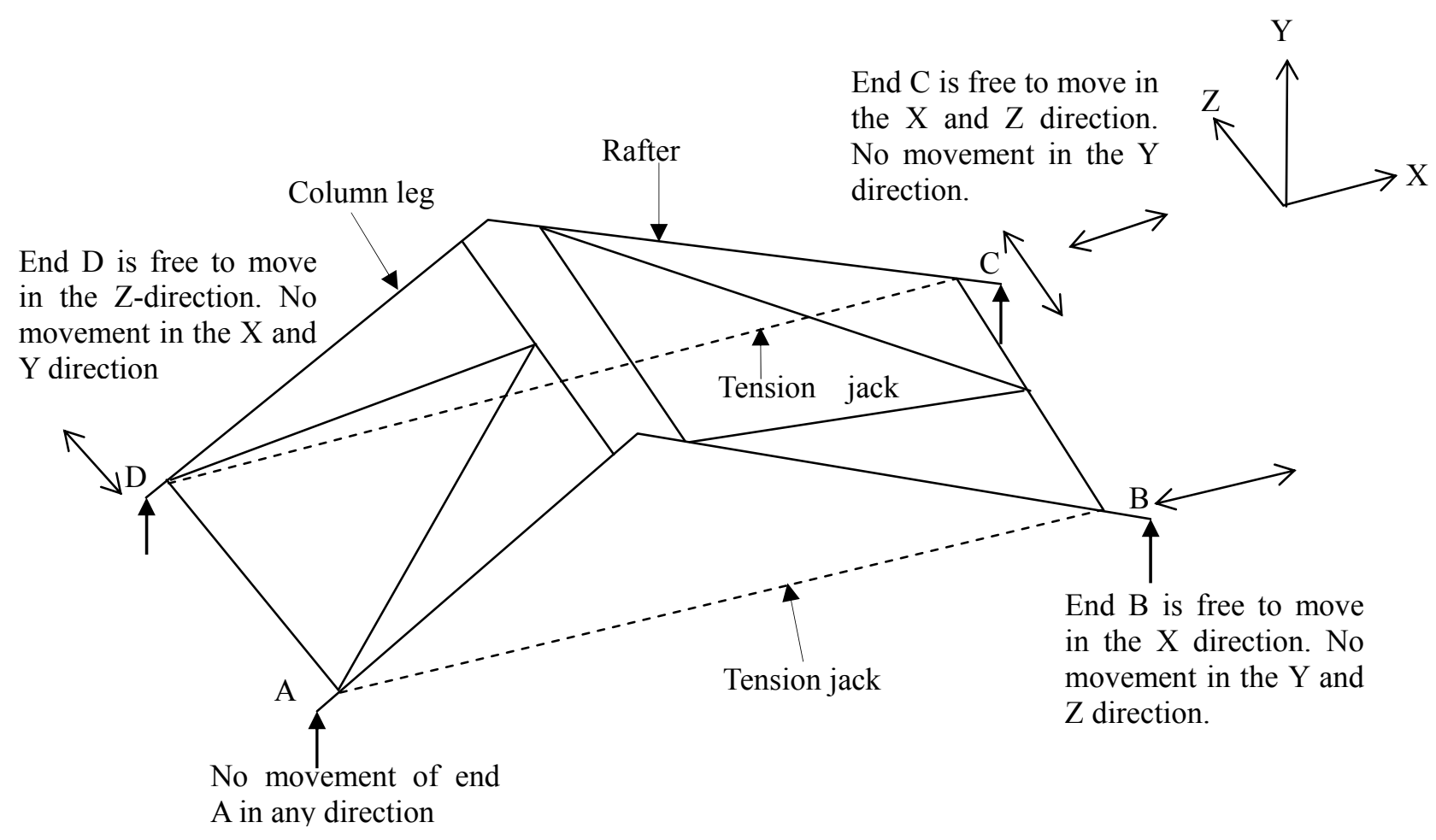

Figure 2. Schematic Test Set-Up 


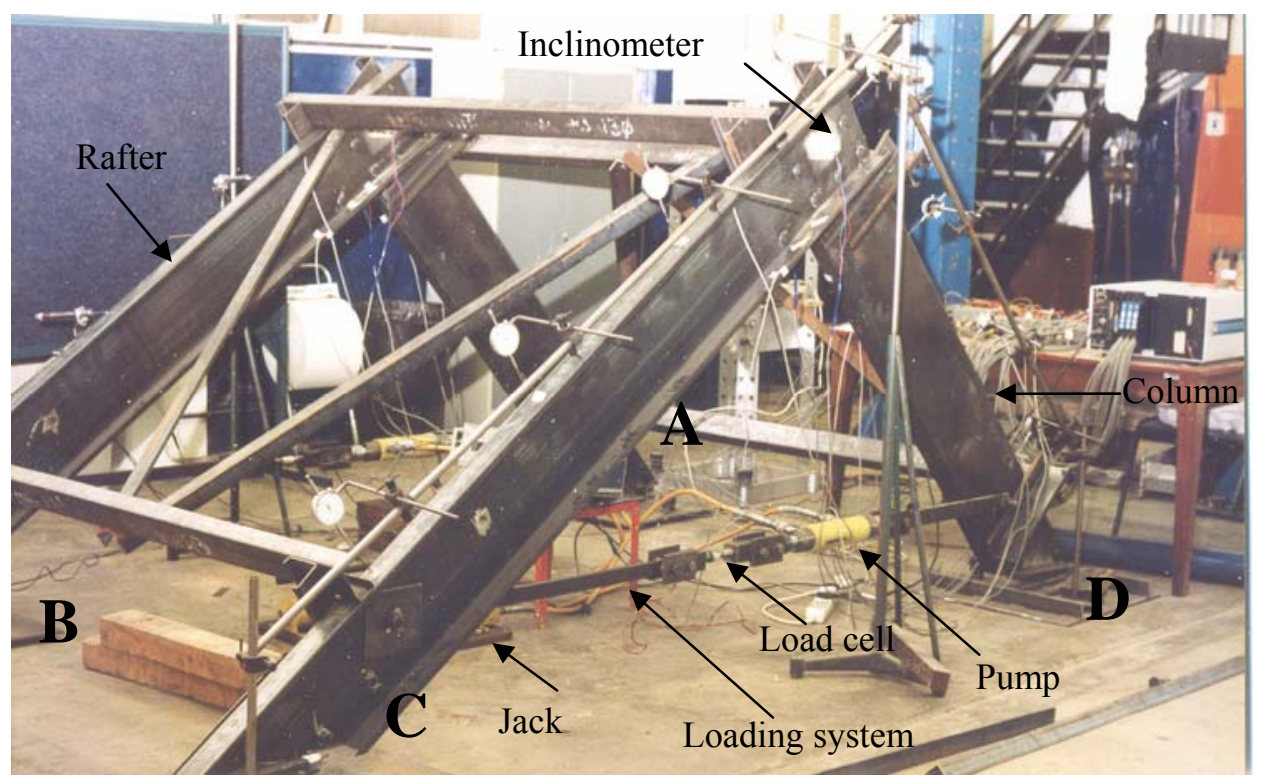

Figure 3. Test Set-Up

Variables in the 4 tests include the number and size of bolts in the connection, and the yield and ultimate strength of the cold-formed channels. A list of these variables and the corresponding structures are given in Table 1 . The study of the results shows that the longitudinal web coupons have on average the smallest yield strength. The behaviour of the longitudinal coupons from the web may be considered consistent with the mechanical properties associated with the virgin steel sheet, suggesting that the cold-rolling operation may have minimally affected that part of the section. The average yield stress for the $300 \times 75 \times 20 \times 3$ and $300 \times 65 \times 20 \times 3$ longitudinal flange coupons are almost the same as that of the longitudinal web coupons. The yield stress for the $300 \times 50 \times 20 \times 3$ flange coupons is $23 \%$ greater than the longitudinal web coupons. This increase is probably influenced by the rolling at the corners of the channels. The smaller the flange width, the more likely will the properties of the flange resemble those at the corners.

The average yield stress for the flange coupons is used to calculate the moment of resistance of the channels, whilst the average ultimate stress for the web coupons is used to calculate the moment of resistance of the connections (Table 3). This is based on the assumption that the flanges resist the moment whilst the web resists the bearing forces in the connections. Young's modulus of elasticity $(\mathrm{E}=207 \mathrm{GPa})$ is used in the buckling calculations. The bolts at the eaves joint were increased to 8 in structure 2 to find out whether this would change the mode of failure of structure 1, which failed due to local buckling as a result of stress concentrations below the inside lower bolt. Increasing the number of bolts would result in a revised distribution of the bolt forces. Details of the bolt configurations of the tested frames are given in Figure 4.

In-plane rotation of eaves' joints was monitored using high-precision digital rotation transducers (also known as AccuStar Electronic Clinometers). The heart of the system is a patented, capacitance-based sensor with no moving parts. When rotated about its sensitive axis, this unique sensor provides an exceedingly linear variation in capacitance, which is electronically converted into angular data. The clinometer has a total range of $\pm 60^{\circ}$ and a linear range of $\pm 45^{\circ}$. All clinometers were calibrated to read $20.3446^{\circ}$ volt. Each clinometer was screwed onto a $70 \times 70 \times 10 \mathrm{~mm}$ piece of wood and then glued to the centre of the joint. All dirt particles were removed from the mounting plane and the mounting of the piece of wood so that the two could bond together well. The centre of each joint was installed with two rotation transducers, with one 
transducer on each side of the joint as shown in Figure 4. The holes of the clinometers were aligned vertically so as to read zero on the multimeter in the unloaded condition.

Table 1. Variables in the Structures

\begin{tabular}{|c|c|c|c|c|c|c|c|c|}
\hline Structure & Section & Span $(\mathrm{m})$ & \multirow{2}{*}{$\begin{array}{c}\text { No. of } \\
\text { Bolts }\end{array}$} & \multirow{2}{*}{$\begin{array}{c}\text { Size of } \\
\text { Bolts }\end{array}$} & & \multicolumn{2}{|c|}{$\mathrm{f}_{\mathrm{y}}$} & \multicolumn{2}{|c|}{$\mathrm{f}_{\mathrm{u}}$} \\
\hline Structure 1 & $300 \times 75 \times 20 \times 3$ & 12 & 4 & M20 & 468.88 & 475.05 & 541.32 & 546.95 \\
\hline Structure 2 & $300 \times 75 \times 20 \times 3$ & 12 & 8 & M20 & 468.88 & 475.05 & 541.32 & 546.95 \\
\hline Structure 3 & $300 \times 65 \times 20 \times 3$ & 11 & 4 & M16 & 344.77 & 346.05 & 473.09 & 473.90 \\
\hline Structure 4 & $300 \times 50 \times 20 \times 3$ & 10 & 4 & M16 & 254.31 & 311.68 & 346.22 & 370.60 \\
\hline
\end{tabular}

LWC - longitudinal web coupon, LFC - longitudinal flange coupon

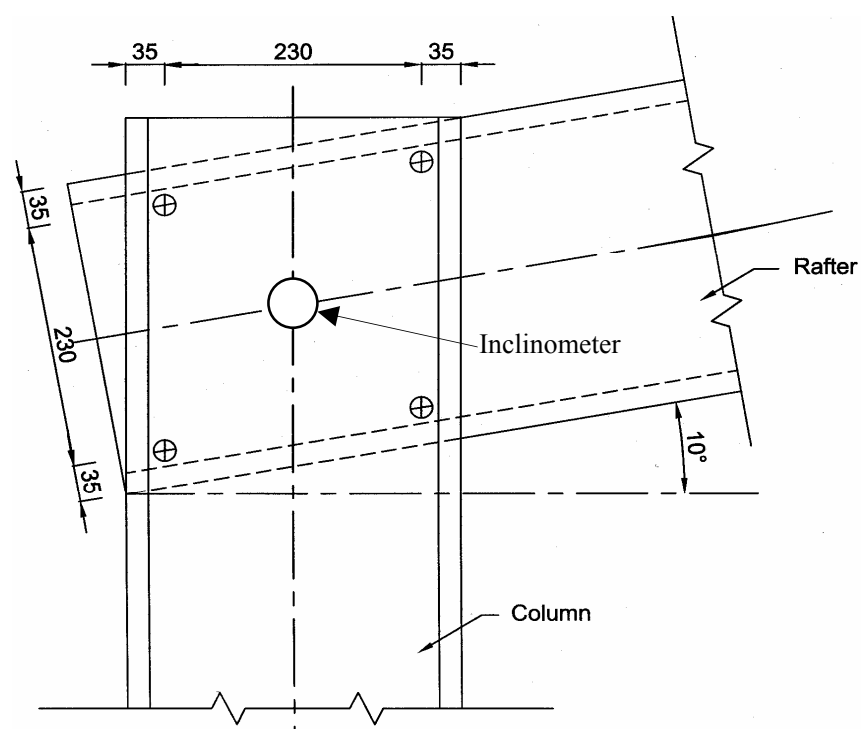

(a) 4-Bolt Connection

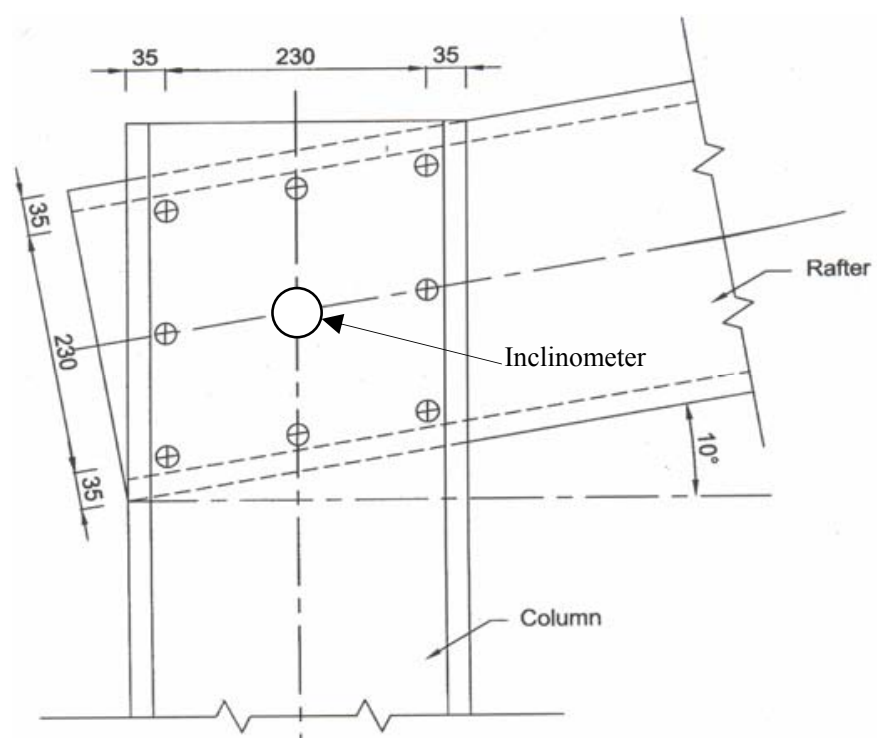

(b) 8-Bolt Connection

Figure 4. Bolt Configurations of Eaves Connections

\section{FAILURE MODES}

The modes of failure of the frames include local buckling of the compression zone of the flange and web of the channels, lateral torsional buckling of the channels between points of lateral support and bolts in bearing. Local buckling was the ultimate failure mode in all tests in virtually the same position, and it occurred after considerable rotation of the channel section at the eaves connection. This considerable rotation is responsible for redistributing moments from the eaves joint to other parts of the frame. A typical local buckling failure is shown in Figure 5 and is initiated in the bottom flange by stress concentrations, shear lag and bearing deformations, directly below the inside lower bolt, followed by buckling of the web. After local buckling, the applied load dropped slowly. 


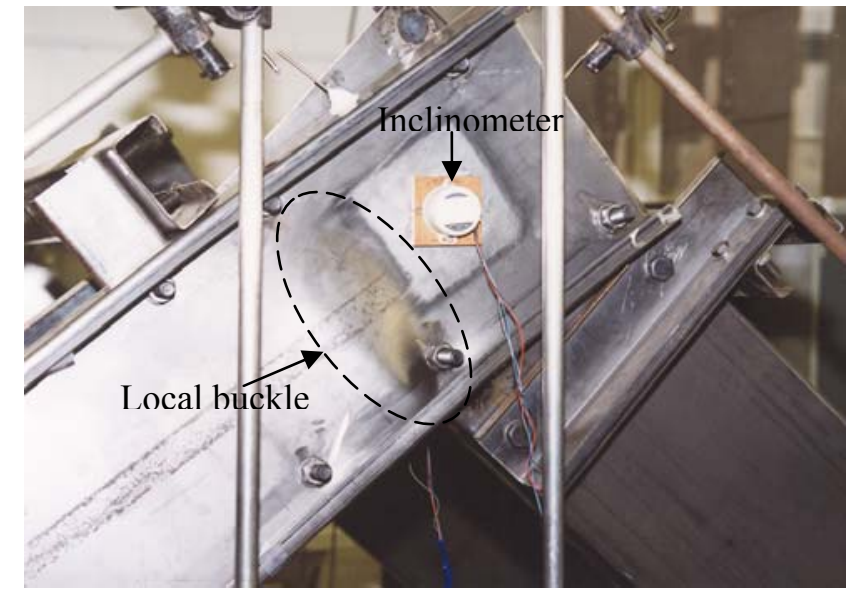

(a) Local Buckling Failure

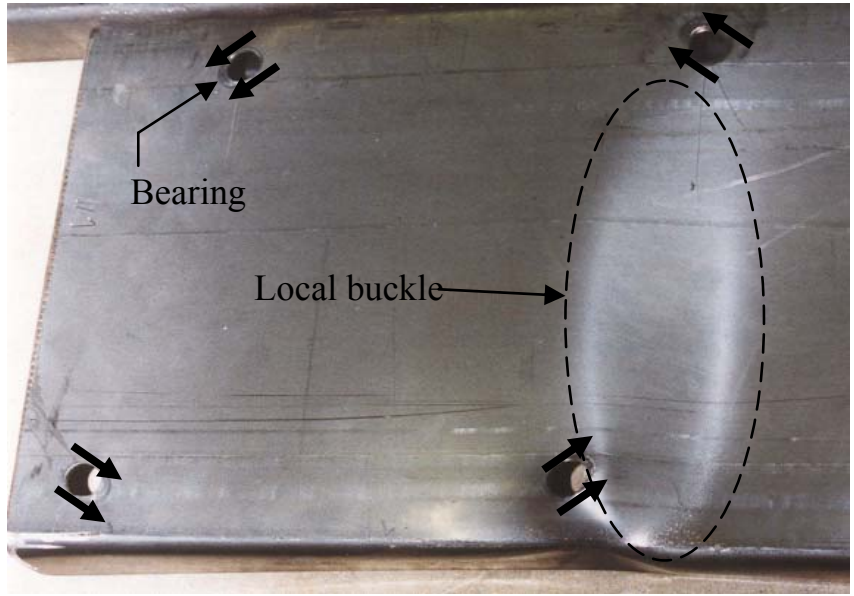

(b) Local Buckling and Bearing deformation

Figure 5. Failure Modes

Lateral-torsional buckling was the second mode of failure of concern. Although the longer laterally unsupported leg (rafter) did not ultimately fail due to lateral-torsional buckling there was considerable lateral movement and twisting of the leg near the maximum load. This was more evident in frames where the points of contraflexure were moved further away from the eaves connection (structures 2, 3 and 4) and narrower flanges were used to promote lateral-torsional instability (structures 3 and 4). Lateral-torsional buckling did not contribute to a loss of moment up to a slenderness ratio $\left(\mathrm{KL} / \mathrm{r}_{\mathrm{y}}\right)$ of about 101 . After testing, the frame members were disassembled for inspection. It was observed that the frames 1, 3 and 4 showed considerable bolt-bearing deformation around the bolt-holes. This type of distortion was more pronounced at the inside lower bolt-hole as shown in Figure 5(b), where the bolt-holes were distorted significantly. The distortions were influenced more by the larger moment than by the resultant of the axial and shear forces. This is demonstrated by the direction of the elongation of the bolt-hole (see arrows in Figure 5(b)). Bearing distortion of steel around bolt-holes is a ductile mode of failure and is intended to provide the ductility required for moment redistribution.

\section{MOMENT-ROTATION GRAPHS}

The flexural behaviour of a connection is best described by the relationship between the moment transmitted by the connection (M) and the relative rotation of the two members fastened by the connection $(\phi)$. The axial and shear deformations are usually small compared to the rotational deformation, consequently, only the connection's rotational deformation was considered. The moment adopted in these graphs is calculated using the initial lever arm between the joint centroid and the line of action of the tension jacks. No secondary effects were considered in calculating this moment. The rotation represents the change in angle between the rafter and the column at the centre of the connection. The slope of the moment-rotation curve is a measure of the rigidity or stiffness of the connection at any particular value of rotation.

Figure 6 show the average graphs for the two connections of each test structure. No rotation of the connections was experienced during the initial stages of loading since the applied load was probably carried by the frictional resistance between the webs of the channels in the connection. This might also have been caused by the fact that, before testing, considerable caution was exercised to make sure that all measuring instruments were working. To achieve this, the structures 
were initially loaded with relatively low intensities of load relative to the estimated failure load until the instrumentation was performing satisfactorily. The response of the connections for structures 1, 3 and 4 became progressively non-linear as ductile bearing distortions took place, in the presence of strain hardening, until failure occurred due to local buckling of the flange of the channel. Although the flange and web of the channel failed in local buckling there was also considerable deformation of the holes in bearing. The moment-rotation response in test 2 with 8 bolts is different from that in structures 1, 3 and 4 with 4 bolts, as the moment-rotation relationship remained largely linear-elastic until failure. The graph shows little evidence of non-linear deformation in the joint. There was no apparent bearing failure of the holes.

All connections except the ones for structure 2 gave a relatively smooth bilinear moment-rotation response, which eventually flattened out, at levels close to the ultimate moment. It can be noted from the moment-rotation curve that none of the tests has a well-defined yield point. The non-linear response and decreasing connection stiffness exhibited late in the loading sequence is attributed, primarily, to local yielding, bolt-bearing deformations and eventual yielding at the flange below the inside bolt. All connections are able to develop continually increasing moments through the full range of rotations imposed during the tests. The maximum rotation for each connection of approximately 0.02 radians is shown in Figure 6 and Table 2 and reflects useful ductility [3]. Considerably more ductility is achieved in mild steel channels (structures 3 and 4) than for high strength material (structures 1 and 2). Thus, there is greater moment redistribution capability in structures 3 and 4 than structures 1 and 2. No significant advantage in ultimate strength is gained by using 8 bolts as in the connections of test 2 .

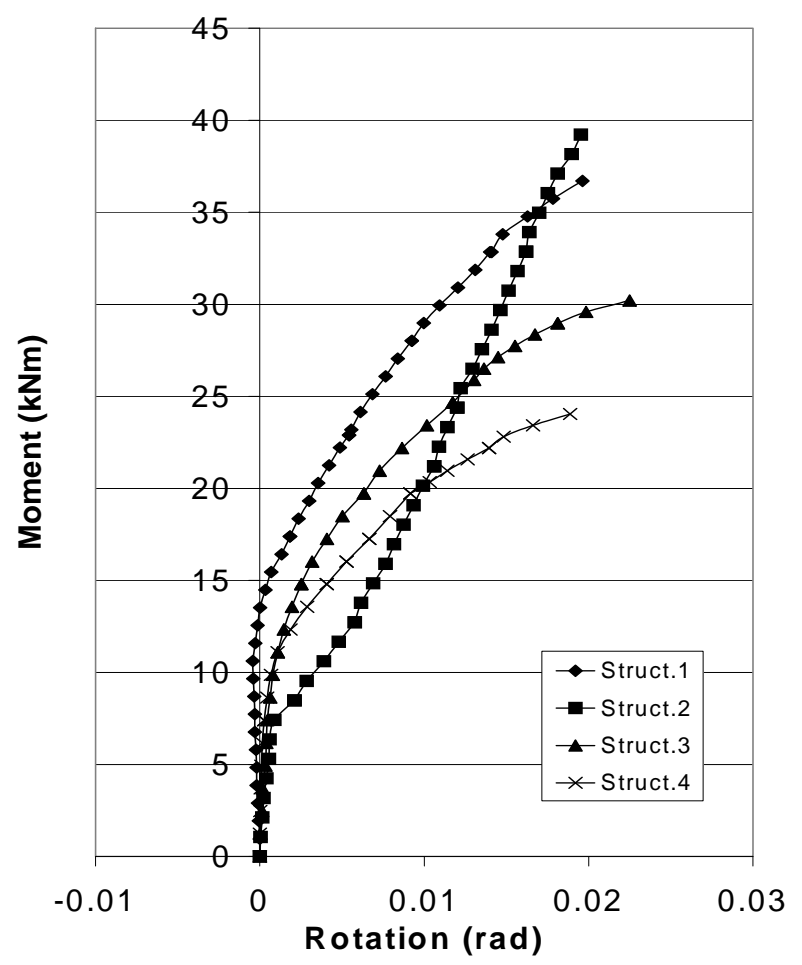

Figure 6. Moment-Rotation Curves 
Table 2. Rotation of Joint

\begin{tabular}{|c|c|c|c|c|c|c|}
\hline Structure & Section & Frames & $\begin{array}{c}\text { Column } \\
\text { rotation }\left(\phi_{\mathrm{c}}\right)\end{array}$ & $\begin{array}{c}\text { Rafter } \\
\text { rotation }\left(\phi_{\mathrm{r}}\right)\end{array}$ & $\begin{array}{c}\text { Joint } \\
\text { rotation }\left(\phi_{\mathrm{j}}\right)\end{array}$ & $\begin{array}{c}\text { Average } \\
\text { joint rotation } \\
\left(\phi_{\mathrm{ja}}\right)\end{array}$ \\
\hline Structure 1 & $300 \times 75 \times 20 \times 3$ & Frame 1 & 0.0105 & 0.0091 & 0.0196 & 0.0196 \\
& & Frame 2 & - & - & - & - \\
\hline Structure 2 & $300 \times 75 \times 20 \times 3$ & Frame 1 & 0.0127 & 0.0055 & 0.0182 & 0.0195 \\
& & Frame 2 & 0.0159 & 0.0049 & 0.0208 & \\
\hline Structure 3 & $300 \times 65 \times 20 \times 3$ & Frame 1 & 0.0116 & 0.0102 & 0.0218 & 0.0225 \\
& & Frame 2 & 0.0139 & 0.0093 & 0.0232 & \\
\hline Structure 4 & $300 \times 50 \times 20 \times 3$ & Frame 1 & 0.0100 & 0.0099 & 0.0199 & 0.0189 \\
& & Frame 2 & 0.0091 & 0.0087 & 0.0178 & \\
\hline
\end{tabular}

\section{ROTATION CAPACITY OF THE FRAMES}

A numerical investigation into the formation of hinges is carried out on the three frames using a mixed flexibility approach. This method simplifies elastic and inelastic structural analysis of frames, and is useful in determining the required inelastic rotation capacity or ductility of these frames and characteristics of semi-rigid connections. It is not the purpose of this paper to describe the mixed flexibility method in detail as this description is available in others papers [4-6]. However, a brief description of the method will be given here.

\subsection{Theory of Solving Unknown Moments}

The mixed flexibility method treats the end moments of all elements in a frame and independent sway deflections as the unknowns. The unknown moments are solved using rotation compatibility and moment equilibrium equations. Consider a substructure in Figure 7(a), with all members meeting at joint $i$. Joint $i$ can be assumed to be located at the point of maximum internal moment or at the centre of the member if no internal maximum moment exists. This makes it possible for inelastic behaviour within the element to be considered with the associated member loads. If element $i j$ is one of two elements in member $i j m$, then other elements meeting at joint $i$ are $i k$, and $i l$. The notation and sign convention for element $i j$ are illustrated in Figure 7(b) based on local $x$ and $y$ axes. Assuming that the displacements are small, the flexibility matrix relating end rotations $\theta$ to end moments $M$ and relative end deflections due to sway $d_{y}$ (all positive anti-clockwise) in element $i j$ is:

$$
\begin{aligned}
\left\{\begin{array}{c}
\theta_{i j} \\
\theta_{j i}
\end{array}\right\} & =\frac{L}{E I}\left[\begin{array}{cc}
1 / 3 & -1 / 6 \\
-1 / 6 & 1 / 3
\end{array}\right]\left\{\begin{array}{l}
M_{i j} \\
M_{j i}
\end{array}\right\}+\left\{\begin{array}{l}
d_{y j i} / L \\
d_{y j i} / L
\end{array}\right\} \\
& =[f]\{M\}+\left\{d_{y j i} / L\right\}
\end{aligned}
$$

where, $[f]$ is the normal flexibility matrix, $L$ and $E I$ are the length and elastic flexural rigidity of the element, respectively, and $d_{y j i}$ is the relative sway deflection normal to the element (see Figure $7(b))$. 

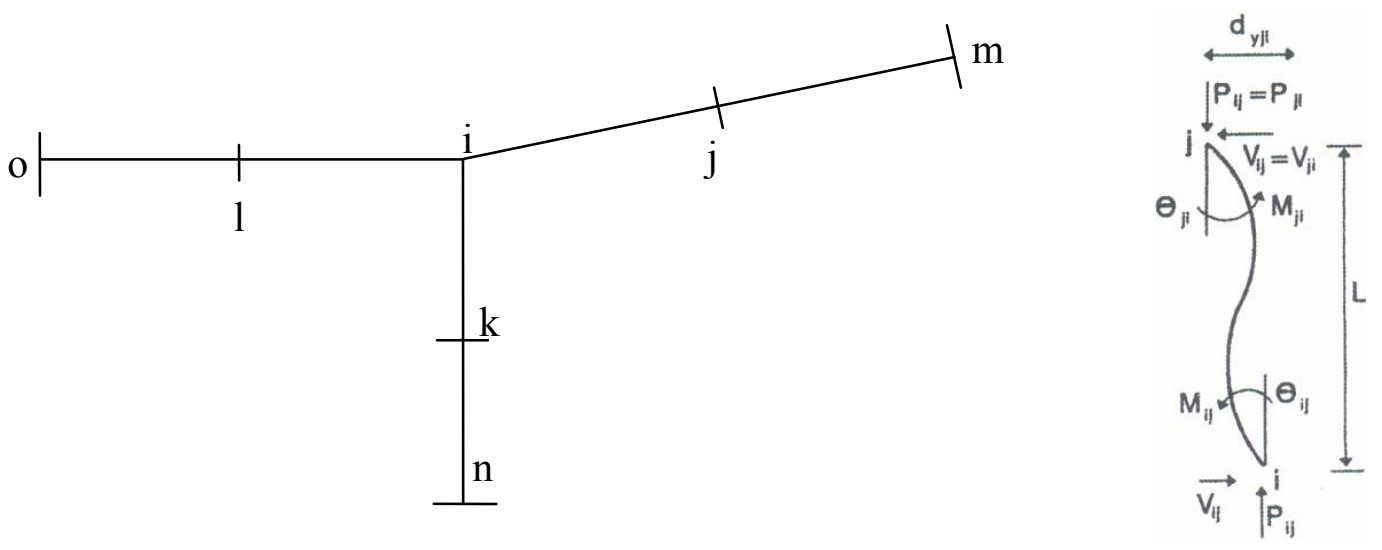

(a) Elements of Substructure

(b) Notation of Element $i j$

Figure 7. Substructure and Notation of Element $i j$

Changes in the flexibility of the element, caused by axial forces, can be accommodated by introducing Berry stability functions, $b_{1}$ and $b_{2}$ into Eq. 1.

$$
\left\{\begin{array}{c}
\theta_{i j} \\
\theta_{j i}
\end{array}\right\}=\frac{L}{E I}\left[\begin{array}{cc}
b_{1} / 3 & -b_{2} / 6 \\
-b_{2} / 6 & b_{1} / 3
\end{array}\right]\left\{\begin{array}{l}
M_{i j} \\
M_{j i}
\end{array}\right\}+\left\{\begin{array}{l}
d_{y j i} / L \\
d_{y j i} / L
\end{array}\right\}
$$

Note that when second-order effects are neglected, the value of $b_{1}=b_{2}=1$. The moments $(n)$ at the end of the elements $(n)$ meeting at joint $i$ can be calculated by initial considering the equilibrium of the end moments at joint $i$, that is,

$$
\sum_{1}^{n} M_{i}=M_{i j}+M_{i k}+M_{i l}=M_{u}
$$

where, $M_{u}$ is the external moment applied at joint $i$. For three elements meeting at joint $i$ in Figure 7(a), there are two (n-1) independent compatibility equations representing equal rotations at end $i$ of elements $i j$ and $i k ; i j$ and $i l$; as follows:

$$
\theta_{t i k}-\theta_{t i j}=0 ; \quad \theta_{t i l}-\theta_{t i j}=0
$$

where, $\theta_{t i j}, \theta_{t i k}, \theta_{t i l}$ are the total rotations at end $i$ of members $i j, i k$, and $i l$, respectively. Each of these total rotations may be calculated using the principle of superposition, for example in element ij:

$$
\theta_{t i j}=\theta_{i j}+\theta_{e i j}+\theta_{y i j}+\theta_{c i j}
$$

where, $\theta_{i j}$ is the elastic end rotation due to the unknown end moments and sway deflections (see Eq. 1), $\theta_{e i j}$ is the elastic end rotation in a simply-supported element due to element loads (i.e. when unknown end moments are equal to zero), $\theta_{y i j}$ is the inelastic rotation at end $i$ of the element, obtained by integrating the inelastic portion of the moment-curvature relationship over the length of the element $i j$, and $\theta_{c i j}$ is the elastic or inelastic rotation due to the end connection at end $i$ of element $i j$. These components of end rotation can be expressed in terms of the unknowns or the applied loads. When considering second-order effects, the end rotations due to the applied loads $\theta_{e i j}$ 
should also be adjusted for axial force using Berry functions. It must be recognised in the compatibility equations for a fixed support that each element has zero rotation.

The derivation of unknown end moments given above is sufficient for a structure without independent modes of sway. For a structure subjected to independent modes of sway refer to Kemp [5]. Several benefits are realized from the mixed flexibility over stiffness methods, namely; unknown moments easily converge towards known ultimate moment capacities, rotation compatibility equations easily accommodate inelastic end connections or inelastic behaviour of the adjacent elements, and that there is no back-substitution to calculate end moments. Equilibrium equations of moments at each joint are expressed in terms of unknown end moments, and these equations do not change in nonlinear analysis. The independent modes of sway deflection are the only unknown components of displacement and relate uniquely to the classical modes of instability, plastic sway or vibration. Axial forces in elements, which form the basis of iteration in nonlinear analysis, are determined by equilibrium considerations from the calculated end moments, and not as a function of small differences in large joint displacements, as is common in the stiffness method. The method requires the same number and arrangement of unknowns as in an elastic analysis. It provides an efficient and accurate solution to general non-linear analysis of steel frames which incorporates yielding and strain hardening of the elements and non-linear behaviour of semi-rigid joints. It also provides a direct calculation of the required inelastic rotation of the hinges in plastic analysis.

\subsection{Application to Cold-Formed Portal Frames}

Inelastic material behaviour is represented by bi-linear moment-rotation relationships, and can accommodate the effects of member loads. Bi-linear moment-rotation relationship models the moment-rotation curves in Figure 6 accurately. To determine the rotation capacity, the moment of resistance of the regions where the hinges are expected to occur had to be determined for the vertical loading case. The regions are denoted by the letters $\mathrm{A}, \mathrm{B}$ and $\mathrm{C}$ in the left half of a symmetrical portal frame, shown in Figure 8, and the moment capacities are given in Table 3. In Table 3, $\mathrm{M}_{\mathrm{y}}$ and $\mathrm{M}_{\mathrm{rb}}$ are the factored cross-sectional and buckling moment of resistance respectively. The buckling moment of resistance $\mathrm{M}_{\mathrm{rb}}$ is determined at the eaves under linear moment gradient in the region $\mathrm{B}$, assuming an effective length factor of 0.85 . It has been indicated before that the ultimate mode of failure of all structures tested was that of local buckling at the joint and that this type of failure was initiated in the bottom flange and web by stress concentrations, shear lag and bearing deformations. This means that the joint was more critical than the members. Local buckling occurred after considerable rotation of the channel section at the eaves connection. A decision was taken to reduce the moment of resistance of the channels so that it almost matches the moment of resistance of the joint. Thus, a factor of 0.8 is applied to $\mathrm{M}_{\mathrm{y}}$ and $\mathrm{M}_{\mathrm{rb}}$ in Table 3, to take account of stress concentrations, shear lag and bearing deformations in the connections [7]. The moment of resistance of the channel at first yield was found to be almost equal to the buckling moment of resistance of the channel. This was a clear indication that the channels were adequately restrained against lateral-torsional buckling. 
Uniformly distributed load

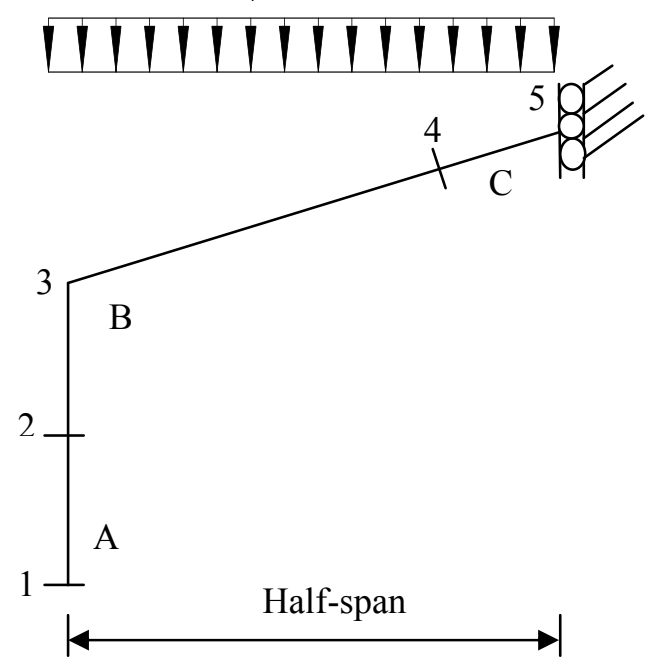

Figure 8. Half-Portal Frame

Table 3. Moment of Resistance of the Frames

\begin{tabular}{|c|c|c|c|c|c|c|c|c|c|}
\hline \multirow[t]{3}{*}{ Frame } & \multirow[t]{3}{*}{ Section } & \multirow{3}{*}{$\begin{array}{l}\text { Span } \\
\text { (m) }\end{array}$} & \multicolumn{7}{|c|}{ Moment of resistance $(\mathrm{kNm})$} \\
\hline & & & Region A & \multicolumn{2}{|c|}{ Region B } & \multicolumn{2}{|c|}{ Region $\mathrm{C}$} & \multirow{2}{*}{$\begin{array}{c}\text { Eaves } \\
\text { joint }\end{array}$} & \multirow{2}{*}{$\begin{array}{c}\text { Apex } \\
\text { joint }\end{array}$} \\
\hline & & & $0.5 \mathrm{M}_{\mathrm{B}}$ & $0.8 \mathrm{M}_{\mathrm{v}}$ & $0.8 \mathrm{M}_{\mathrm{rb}}$ & $0.8 \mathrm{M}_{\mathrm{v}}$ & $0.8 \mathrm{M}_{\mathrm{rb}}$ & & \\
\hline 1 & $300 \times 75 \times 20 \times 3$ & 10 & 9.39 & 19.64 & $18.78^{\mathrm{B}}$ & 19.64 & $17.93^{\mathrm{C}}$ & 22.35 & 22.76 \\
\hline 2 & $300 \times 65 \times 20 \times 3$ & 11 & 13.13 & 26.70 & $26.26^{\mathrm{B}}$ & 26.70 & $25.00^{\mathrm{C}}$ & 30.54 & 31.11 \\
\hline 3 & $300 \times 50 \times 20 \times 3$ & 12 & 17.48 & 37.13 & 35.86 & 37.13 & $33.58^{\mathrm{C}}$ & $34.95^{\mathrm{B}}$ & 35.60 \\
\hline
\end{tabular}

The critical moment of resistance of a particular region is used in the plastic analysis of the frames. This analysis is done for $50 \%$ base fixity and pinned base conditions. The moment capacity of the base is made half the moment capacity of the eaves joint following investigation by Robertson [8], and Heldt and Mahendran [9]. The investigations showed that a bolted base is about $50 \%$ fixed (having stiffness halfway between fixed and pinned conditions). This situation puts the base connection at between $40 \%-50 \%$ of the eaves connection. Possible points of hinge formation are numbered 1-5 in the portal frames considered (see Figure 8). As indicated in the derivation of unknown end moments, instability and inelastic behavior within the length of a member can be considered by providing one additional joint within the length of that particular member. The load and moments that cause the hinges to occur and the actual points where hinges are formed are given in Table 4 . The hinge at 6 occurs between points 4 and 5 in Figure 8.

In the lower bound analysis [4-6] the first hinge develops at point 1 because the relative moment capacity at that point is less than other points. The load causing the second hinge to form at 3 is slightly less for a pinned base than for a partially fixed base. The collapse loads in Table 4 are much greater than the factored applied ultimate load of $2.92 \mathrm{kN} / \mathrm{m}$. Collapse occurs when the third hinge forms between points 4 and 5 in Figure 8. The plastic rotations required for the three frames at hinges 1 and 3 are shown in Table 5. The required hinge rotations at failure of the pinned base are less than that of the partially fixed base. The largest hinge rotations are required at hinge 3 . Considering all 3 frames and both foundation conditions it is apparent from Table 5 that plastic collapse will develop if the available plastic hinge rotation $\theta_{\mathrm{p}}$ at 3 is between 0.01 and 0.02 radians. This rotation was achieved by all the structures tested, showing that plastic collapse is feasible. 
Table 4. Load, Moment and Points of Hinge Formation

\begin{tabular}{|c|c|c|c|c|c|c|c|c|c|}
\hline \multirow[t]{2}{*}{ Frame } & \multirow[t]{2}{*}{ Section } & \multirow{2}{*}{$\begin{array}{l}\text { Span } \\
\text { (m) }\end{array}$} & \multirow{2}{*}{$\begin{array}{l}\text { Base } \\
\text { fixity }\end{array}$} & \multicolumn{2}{|c|}{ Hinge 1} & \multicolumn{2}{|c|}{ Hinge 3} & \multicolumn{2}{|c|}{ Hinge 6} \\
\hline & & & & $\begin{array}{c}\text { Load } \\
(\mathrm{kN} / \mathrm{m})\end{array}$ & $\begin{array}{c}\text { Moment } \\
(\mathrm{kNm})\end{array}$ & $\begin{array}{c}\text { Load } \\
(\mathrm{kN} / \mathrm{m})\end{array}$ & $\begin{array}{c}\text { Moment } \\
(\mathrm{kNm})\end{array}$ & $\begin{array}{c}\text { Load } \\
(\mathrm{kN} / \mathrm{m})\end{array}$ & $\begin{array}{c}\text { Moment } \\
(\mathrm{kNm})\end{array}$ \\
\hline \multirow[t]{2}{*}{1} & \multirow[t]{2}{*}{$300 \times 75 \times 20 \times 3$} & \multirow[t]{2}{*}{10} & $50 \%$ & 2.05 & -9.39 & 3.03 & 18.78 & 3.58 & 18.78 \\
\hline & & & $0 \%$ & - & - & 2.95 & 18.78 & 3.36 & 18.78 \\
\hline \multirow[t]{2}{*}{2} & \multirow[t]{2}{*}{$300 \times 65 \times 20 \times 3$} & \multirow[t]{2}{*}{11} & $50 \%$ & 2.30 & -13.13 & 3.52 & 26.26 & 4.20 & 26.26 \\
\hline & & & $0 \%$ & - & - & 3.40 & 26.26 & 3.93 & 26.26 \\
\hline \multirow[t]{2}{*}{3} & \multirow[t]{2}{*}{$300 \times 50 \times 20 \times 3$} & \multirow[t]{2}{*}{12} & $50 \%$ & 2.51 & -17.48 & 3.97 & 34.95 & 4.81 & 34.95 \\
\hline & & & $0 \%$ & - & - & 3.90 & 35.86 & 4.54 & 35.86 \\
\hline
\end{tabular}

Table 5. Plastic Rotation

\begin{tabular}{|c|c|c|c|c|c|c|}
\hline \multirow[t]{2}{*}{ Frame } & \multirow[t]{2}{*}{ Section } & \multirow{2}{*}{$\begin{array}{l}\text { Span } \\
\text { (m) }\end{array}$} & \multirow[t]{2}{*}{ Base fixity } & \multirow{2}{*}{$\begin{array}{l}\text { Plastic collapse } \\
\text { load }(\mathrm{kN} / \mathrm{m})\end{array}$} & Hinge 1 & Hinge 3 \\
\hline & & & & & $\theta_{\mathrm{p}}$ & $\theta_{\mathrm{p}}$ \\
\hline \multirow[t]{2}{*}{1} & \multirow[t]{2}{*}{$300 \times 75 \times 20 \times 3$} & \multirow[t]{2}{*}{10} & $50 \%$ & 3.58 & 0.0032 & 0.009 \\
\hline & & & $0 \%$ & 3.36 & - & 0.007 \\
\hline \multirow[t]{2}{*}{2} & \multirow[t]{2}{*}{$300 \times 65 \times 20 \times 3$} & \multirow[t]{2}{*}{11} & $50 \%$ & 4.20 & 0.0048 & 0.015 \\
\hline & & & $0 \%$ & 3.93 & - & 0.011 \\
\hline \multirow[t]{2}{*}{3} & \multirow[t]{2}{*}{$300 \times 50 \times 20 \times 3$} & \multirow[t]{2}{*}{12} & $50 \%$ & 4.81 & 0.0071 & 0.021 \\
\hline & & & $0 \%$ & 4.54 & - & 0.016 \\
\hline
\end{tabular}

\section{CONCLUSION}

The tests demonstrate the considerable ductility that is achieved in the back-to-back bolted connections, which should be sufficient in many cases to accommodate plastic analysis of the portal frames. Adjacent column and rafter channels are oriented in opposite directions to take advantage of the counter-balancing moments and forces in the back-to-back connections. This system is important in enhancing the lateral buckling strength of the channels. Three modes of failure were observed [7], namely: local buckling of the compression zone of the flange and web of the channels, lateral torsional buckling of the channels between points of lateral support and bolts in bearing. The source of failure in all structures was local buckling of the compression flange and web. This occurred after considerable rotation of the channel sections within the eaves connection. Local buckling was made more critical by stress concentrations, shear lag and bearing deformations caused by back-to-back bolted connections.

Test observation shows joint resistance to be critical. This is necessary for inelastic rotation. The experimental maximum rotation of the connections of approximately 0.02 radians shows that there is substantial ductility that can be salvaged from cold-formed portal frames. Figure 6 also shows that considerably more ductility is achieved in mild steel channels (structures 3 and 4) than for high strength material (structures 1 and 2). This implies that there is greater moment redistribution capability in structures 3 and 4 than structures 1 and 2. As indicated previously, no significant advantage in ultimate strength is gained by using 8 bolts as in the connections of test 2 .

Kemp's mixed flexibility approach [4-6] is used to determine the required inelastic rotation of the hinges rotations of the three frames at the eaves joints. The analysis is done for both $50 \%$ base fixity and pinned base conditions. The collapse loads in Table 4 are much greater than the factored applied ultimate load of $2.92 \mathrm{kN} / \mathrm{m}$ (Table 3) used to design these frames. It is apparent from Table 
5 that plastic collapse will develop if the available plastic hinge rotation $\theta_{\mathrm{p}}$ at 3 is between 0.01 and 0.02 radians. This rotation was achieved by all the structures tested, showing that plastic collapse is feasible. A comparison of the experimental and theoretical rotations shows that they are within the same range.

\section{References}

[1] SANS 10162-2., "South Africa Standard Code of Practice for the Structural Use of Steel, Part 2 - Limit States Design of Cold-formed Steelwork", South African Bureau of Standards, Pretoria, 2005.

[2] CAN/CSA-S16-01., "Steel Structures for Buildings - Limit States Design, Canadian Standards Association, Rexdale (ON), 2001.

[3] Chen, W.F. "Practical Aanalysis for Semi-rigid Frame Design", World Scientific, 2000.

[4] Kemp, A.R., "A Mixed Flexibility Approach for Simplifying Elastic and Inelastic Structural Analysis of Frames", Journal of Construction Steel Research, 2002, Vol. 58, pp. 1297-1313.

[5] Kemp, A.R., "Compatibility Relationships in a Mixed Flexibility-based Method of Frame Analysis", Engineering Structures, 1997, Vol. 19, No. 3, pp. 267-275.

[6] Kemp, A.R., "A Consistent Mixed Approach to Computer Analysis of Frames", Civil Eng. South Africa, 1989, Vol. 30 No. 7, pp. 317-322.

[7] Dundu, M. and Kemp, A.R., "Strength Requirements of Single Cold-formed Channels Connected Back-to-back", Journal of Construction Steel Research, 2006, Vol. 62, pp. 250-261.

[8] Robertson, A.P., “A Study of Base Fixity Effects on Portal Frame Behavior”, The Structural Engineer, 1991, Vol. 69, No. 2, pp. 17-24.

[9] Heldt, T.J. and Mahendran, M., "Full Scale Experiments of a Steel Portal Frame Building", Australian Institute of Steel Construction, 1998, Vol. 32 No. 4, pp. 2-15. 